\title{
Acknowledgments in Neurology research articles: A contrastive study (English - Spanish)
}

\author{
María Ángeles Alcaraz
}

\begin{abstract}
This article reports the findings of a content analysis of acknowledgments, authorship and collaboration practices in a medical corpus made up of 100 English-and 100 Spanish-written research papers, distributed in five blocks of 20 papers each, and randomly drawn in the period 2001-2012 from BMC Neurology and Revista Española de Neurología, two of the leading Neurology journals in their respective languages. In order to discover the similarities and differences between both samples, the objective of this contrastive research was three-fold: 1) to analyse the frequency, length and types of acknowledgments; 2 ) to examine the number of authors, sub-authors and unnamed individuals mentioned in the subtitles, acknowledgment sections, annexes and appendices of the research papers included in the whole sample; and 3) to explore the different types of collaboration among all the participants involved in the research. Although the types of acknowledgments are similar in both contexts, the English-medium sample presents more research papers with acknowledgments, more acknowledgments and longer acknowledgments. In both corpora public funding is the component which receives most acknowledgements, although again much more in English than in Spanish. Of the many people involved in the investigation, Spanish-speaking authors are more numerous than English-speaking authors, whereas English sub-authors and unnamed individuals outnumber their Spanish counterparts. As for the different types of collaboration, in the two samples 'local' collaboration clearly predominates above the remaining variants. Possible explanations for the differences and similarities observed, among them a possible correlation between the higher presence of acknowledgments and the research published in English, are provided. The results presented here give some hints about the collaboration and communication practices followed by two different language scientific communities.
\end{abstract}

Keywords medicine, neurology, research papers, contrastive analysis, English - Spanish, acknowledgments.

\section{Introduction}

Acknowledgments, which allow researchers to reflect their gratitude to all those who helped them in performing their research, found their origin in the thanks expressed to patrons and powerful benefactors in the covering letters accompanying scientific articles (Atkinson 1999). As a matter of fact, they emerged in scientific research papers in 1940 but only became a standard practice in the 1960s (Giannoni 2002, Hyland 2004). Since then, they have had an increasing presence in published research articles as they appear in about half of them in certain disciplines (Cronin et al. 1992).

Acknowledgments, from now on abbreviated as ACKs, have been named in various ways. For example, they have been viewed as "sub-authorship collaboration" (Patel 1973: 81), "expressions of solidarity" (Ben-Ari 1987: 137), "paratexts" (Genette 1997: 3), or "parking lots for miscellaneous contributions" (Cronin 2005: 56). Whichever the label adopted, it cannot be denied that ACKs are a rhetorical collegial space, where authors repay their "intellectual 
indebtedness" (Davis/Cronin 1993: 591) and where the personal and the public, the social and the professional, and the academic and the lay are linked (Hyland 2003).

As a consequence of the interest aroused by ACKs, they have been studied from different angles. Their social significance has been approached, for example, in Biology, Chemistry, Psychology and Political Sciences (Heffner 1981), in Genetics (McCain 1991), in Biology and Economics (Laband et al. 2002), in Chemistry, History, Information Sciences, Philosophy, Psychology, and Sociology (Cronin 1995, Cronin et al. 2004), or in Computer Sciences (Giles/ Councill 2004, Cronin/Franks 2006). Their use and structure have also been analysed in PhD and MA theses (Hyland 2003, Hyland 2004, Gesuato 2004, Hyland/Tse 2004), and their behaviour has been examined in cross-linguistic studies such as those performed by Giannoni (2002) and Salager-Meyer et al. (2009, 2010, 2011).

\section{Purpose and corpus}

From this review of the literature on ACKs, it is clear that research on this issue has been performed in different fields, disciplines and languages. However, it has usually been approached from a general point of view and, as far as I know, studies on sub-disciplines are not very common. My knowledge of English- and Spanish-written medical discourse and the fact that I am subscribed to a Spanish-written journal of Neurology led me to choose this medical sub-discipline, published in both English and Spanish. An additional advantage was that the two journals from which I draw my corpus are open access and free of charge.

In order to discover the similarities and differences between both samples, my aim in this study was three-fold: 1) to analyse the frequency, length and types of acknowledgments; 2) to examine the number of authors, sub-authors and unnamed individuals mentioned in the ACKs and other textual spaces, such as subtitles, annexes and appendices; and 3) to explore the different collaboration practices among the participants involved in the research. To achieve these objectives, I performed a contrastive analysis of a sample of English and Spanish research papers (RPs) published in two large-circulation journals in the field of Neurology, BMC Neurology and Revista Española de Neurología. Both journals are leading journals in the field of Neurology in their respective language and they are also indexed in several international databases such as MEDLINE, EMBASE, or Science Citation Index, to name just a few.

The corpus examined consists of 200 randomly selected RPs (100 in English and 100 in Spanish), published between 2001 and 2012 and distributed in five blocks of 20 papers each: block A (2001), block B (2004), block C (2007), block D (2009), and block E (2012). The year 2001 was chosen as the starting point because it was the launching date of BMC Neurology on the Internet.

The article-selection procedure followed and the similar textual concepts (i. e. ACKs, subtitles, annexes and appendixes) examined allow me to state that the two corpora are parallel/ comparable/equivalent ${ }^{1}$ to the maximum degree (Moreno 2008) and that the tertium comparationis criterion recommended in studies of this kind is amply met:

1 Parallel corpora are defined as sets of comparable original texts written independently in two or more languages, and the notion of comparability is equated to the concept of equivalence (Connor/Moreno 2005: 155). 
- The corpus analysed here covers a well-established genre of medical writing, i.e. research papers.

- The published papers have undergone a strict peer review and editorial scrutiny.

- The examined period is the same for both samples (2001-2012).

- The two journals are leading medical journals in their field of specialization and are comparable in caliber and reputation.

- Both journals are indexed in several international databases and require that the persons/centres/entities that collaborated or supported the research be acknowledged.

- The two journals have a relatively high impact factor (BMC Neurology: 2.17, Revista Española de Neurología: 1.083).

- Both journals are open access.

\section{Methodology}

This study combines both quantitative and qualitative methods of analysis in a complementary manner. In each sample, the quantitative procedures include average distributions, frequencies and percentages, whereas the qualitative procedures provide the explanations for the differences and similarities observed between the two analysed samples.

The motivations that underpinned ACKs were classified according to the seven-part typology already used in previous studies (see, for example, Salager-Meyer et al. 2010):

1. Financial support (recognition of national and/or international funding from private and/ or public sources).

2. Instrumental/technical support (providing access to tools, facilities, specimen samples, technologies, and infrastructural resource; furnishing technical expertise, help in data collection/entry/management, sample preparation, etc.).

3. Conceptual support, also called "peer-interactive communication" (McCain 1991: 512) or "academic support" (Hyland 2003: 244), such as proffering thanks for advice and discussion, comments on the manuscript, critical insight, intellectual guidance, valuable suggestions, assessment on study soundness, etc.

4. Editorial/linguistic support (editing, proofreading, or translating the manuscript).

5. Clerical support (secretarial services).

6. Moral support (thanking someone for his or her enthusiasm, dedication, wisdom).

7. Unclassifiable when it proved impossible to categorize an ACK according to any of the aforementioned categories because of inherent ambiguity, vagueness, or lack of contextual clues.

The following examples drawn from the English corpus illustrate the different types of ACKs:

(1.) This study was supported, in part, by grants from the Harvard Center for Neurodegeneration (Dr Selim) and the Doris Duke Charitable Foundation, the NINDS (1R01NS04504901A1) and the Dana Foundation (Dr Schlaug). (public and private fundings)

(2.) The authors are grateful to Mrs V. Rappelsberger for skilled laboratory work and to Mr E. Mitter-Ferstl, for secretarial assistance. (instrumental and clerical supports)

(3.) The authors wish to thank GNIF research assistants/consultants Elissa Hamlat, Ulysses Labilles, Mattew Przyborsky, and Celia Mazza for their suggestions and editing support. (conceptual and editorial supports)

(4.) The authors would like to thank the staff of the Center for Genomic Sciences and Carol Chieffe for help and encouragement. (moral support) 
(5.) We would like to thank I. Ollech, R. Lürding, I. Gebauer, A. Ebner, T. May and J. Rambeck for their help. (unclassifiable support)

Apart from the ACK sections, other textual spaces, such as subtitles, annexes and appendices, were also examined in order to record the number of authors, sub-authors, unnamed individuals and collaboration practices.

\section{Results and Discussion}

\subsection{ACK frequency and length}

According to table 1, the highest frequency of research papers (RPs) with ACKs was found in the English sample, where it more than doubles the frequency recorded in the Spanish sample. If we compare our results with previous studies, we can see that the frequency of RPs with ACKs in the English corpus is lower than that reported by McCain (1991) in genetics (95\%) and by Hyland (2003) in MA theses and PhD dissertations across a range of hard and soft disciplines, where $90 \%$ of the texts contained an ACK statement. However, it is higher than the English set analysed by Cronin et al. (2004) in Psychology (49 \%) and in Chemistry (75 \%), and by Salager-Meyer et al. (2010) in Medicine (82\%). As for the Spanish sample, the percentage of RPs with ACKs is also higher than the $26 \%$ found by Salager-Meyer et al. (2010). The difference between the corpora examined in this study and Salager-Meyer et al. (2010) is probably due to the fact that, on the one hand, the RPs examined were selected from generalist medical journals and, on the other, in the time band 2005-2007. Table 1 also shows that the number of RPs with ACKs in the English set is much greater than that of RPs without them, whereas RPs without ACKs in the Spanish sample outnumber those that include it. In this sense it could be stated that the expression of gratitude in the English-published research community is more widely spread than it is in its Spanish counterpart.

As the English-written RPs with ACKs are much more frequent than their Spanish counterpart, the number of ACKs and of words making up the ACK spaces are consequently much greater in the English set than in the Spanish set. ${ }^{2}$ Table 1 further illustrates that the average ACK length obtained in the English corpus is slightly higher than the 42 words recorded by Giannoni (1998) in hard sciences (Biology, Mathematics, Medicine), but much lower than the 67 words documented by the same author (Giannoni 2006) in soft sciences (Applied Linguistics, Economics and Social Sciences), or the 83 words found by Salager-Meyer et al. (2010) in Medicine. In MA theses and PhD dissertations (Hyland 2003), ACKs are even longer (160 words on average). As for the Spanish sample, the average length of ACKs is still lower than the 54 words obtained in Medicine by Salager-Meyer et al. (2010).

2 The total number of ACK statements is superior to the number of RPs with ACKs because RPs usually provide more than one reason for acknowledging: a funding agency, technical, instrumental, moral supports, etc. 
Tab. 1: Number of RPs with ACKs, ACK frequency, ACK length and word average per ACK in English and Spanish RPS

\begin{tabular}{|l|c|c|c|}
\hline & English & Spanish & Total \\
\hline RPs with ACKs & $88(88 \%)$ & $41(41 \%)$ & 129 \\
\hline No. of ACKs & 348 & 92 & 440 \\
\hline ACK length (no. of words) & 4371 & 1402 & 5773 \\
\hline Word average per ACK & 49.67 & 34.20 & \\
\hline
\end{tabular}

In the English set, it is interesting to note that the 12 RPs without ACKs were written by authors living in countries where English is not spoken as a native language: China (1 RP), Denmark (1 RP), Germany (2 RPs), Japan (1 RP), South Korea (1 RP), Pakistan (2 RPs), Singapore (1 RP), Taiwan (1 RP), and The Netherlands (2 RPs). The absence of ACKs in these 12 RPs may be due to the fact that all of them were written by only two authors who probably performed their research on their own without others' help. The remaining RPs with ACKs were all written by either native or non-native English-speakers (for a full account of the different countries involved, see section 4.4 on the different types of collaboration). As for the RPs without ACKs published in Revista Española de Neurología, it may be that their authors failed to recognize their debts towards their colleagues, or really did not have anybody to acknowledge.

\subsection{Types of acknowledgments}

According to table 2, the component which receives more ACKs in both corpora is related to financial support, which covers grants, scholarships and funds received either from public sources (universities, national and/or local governments) or private entities (foundations, agencies, pharmaceutical industry). The fact that financial support is the most acknowledged type of funding in the whole sample reflects that scientific progress is only possible thanks to economic help and that this support is crucial in today's biomedical activities.

Tab. 2: ACK types and frequency in English and Spanish RPs

\begin{tabular}{|l|c|c|}
\hline ACK type & English & Spanish \\
\hline Financial & $\begin{array}{c}208(132 \text { public }+76 \text { private }) \\
\text { in 69 RPs }\end{array}$ & $\begin{array}{c}47 \text { (33 public }+14 \text { private }) \text { in } \\
27 \text { RPs }\end{array}$ \\
\hline Instrumental & 79 & 28 \\
\hline Conceptual & 31 & 7 \\
\hline Editorial & 17 & 0 \\
\hline Unclassified & 9 & 4 \\
\hline Moral & 2 & 6 \\
\hline Clerical & 2 & 92 \\
\hline Total & 348 & 0 \\
\hline
\end{tabular}

Nevertheless, financial support reaches the medical English community much more than its Spanish counterpart, which would reveal that the Spanish-speaking scientific world is main- 
ly non-sponsored by either official or private institutions, therefore resembling research in past times when scientists usually worked alone, without any help. Moreover, public funding by far outnumbers private funding in both samples, which would not corroborate previous claims that, for example, in the US context it is the private sector that finances the majority of research (Beckelman et al. 2003). However, in some developing countries research funding is mainly assumed by the public sector (Nour 2005), a statement which would also apply to Spain where most medical research is conducted in public and university hospitals as well (this would explain the origin of the funds received).

The second most frequent ACK component is the technical/instrumental one, which deals with the help received in areas such as capture and analysis of data, use of institutional facilities (equipment and libraries), or samples from pharmaceutical laboratories. Here again, the data from the English sample are higher than those from the Spanish sample.

Conceptual recognition is the third motivation of ACKs in the English sample, but it is the fifth in the Spanish set, where the third and fourth motivations correspond to the "unclassifiable" and "moral" categories. Moral support, which allows researchers to thank their friends for their encouragement, carries interpersonal considerations because it demonstrates how the acknowledgers present themselves as active participants not only in their academic community, but also in a wider social community. The results regarding the frequency of ACKs voiced at conceptual support in both biomedical corpora are similar to those displayed in previous ACK research in medicine (Salager-Meyer et al. 2009, 2010, 2011). However, they are at variance with those found in other fields by other authors (Heffner 1981, McCain 1991, Cronin 1995, Cronin et al. 2004, Laband et al. 2002, Giles/Councill 2004, Cronin/Franks 2006), where conceptual support was found to be the most frequently acknowledged type of help. In PhD dissertations and MA theses (Hyland 2003, 2004, Gesuato 2004, Hyland/Tse 2004), conceptual support was also found to predominate. It could thus be deduced that the predominance of this type of support above the other kinds of expressions of gratitude runs parallel with the field concerned, i.e. what holds in economics or genetics, for example, does not hold in medicine in general or in neurology in particular.

The fourth most frequent ACK-motivation in the English sample corresponds to the editorial/linguistics category, which is non-existent in the Spanish corpus, as is clerical support. It is not surprising to find ACKs documenting editorial assistance in the English corpus because the 11 articles including it were written by non-native English authors living in the following countries and who very likely resorted to some form of proofreading or editing services: Belgium (1 RP), Germany (2 RPs), Italy (3 RPs), Pakistan (1 RP), Spain (2 RPs), Switzerland (1 $\mathrm{RP})$, and Thailand (1 RP). The presence of this ACK-category in the BMC Journal of Neurology would reflect the internationality of this journal which publishes papers written by authors from all over the world.

\subsection{Authorship, sub-authorship, and unnamed individuals}

Before dealing with this sub-section, it is necessary to mention the procedure I followed to obtain the corresponding quantitative data, which can be seen in table 3 . On the one hand, the category "authorship" includes the authors mentioned not only in the subtitles of all the RPs, but also those found in the ACK spaces as well as in annexes and appendices, whose help was required for "assessing quality of the survey data, and when deemed valuable, extracting and providing information from surveys and administrative support" (de Pedro-Cuesta et al. 
2009). The category "sub-authorship" refers to scientists who did not make any important decision as they only participated to the study by sending, for example, the data they had collected about the incidence of a given disease in their place of work to the authors of the publication who gathered and analysed them, and reached the final results. As its name reads, the label "unnamed individuals" does not mention any name and applies to patients who took part in the study, family caregivers, volunteers, and/or hospital staff (general practitioners, residents, nurses, laboratory technicians) who helped in recruiting patients, collecting samples/ data, carrying statistical analyses, supplying and/or looking for references.

Tab. 3: Authorship, sub-authorship and unnamed individuals in English and Spanish RPs

\begin{tabular}{|l|c|c|}
\hline Individual type & English & Spanish \\
\hline Authorship & 672 & 883 \\
\hline Sub-authorship & 342 & 126 \\
\hline Unnamed & 55 & 24 \\
\hline Total & 1069 & 1033 \\
\hline
\end{tabular}

According to table 3, the number of individuals involved in the research is quite high in both samples, although slightly higher in English than in Spanish. Spanish authorship outnumbers English authorship, whereas English sub-authorship outnumbers Spanish sub-authorship. Unnamed individuals are found in both corpora, although again much more frequently in the English corpus than in the Spanish one. The figures displayed in table 3 would then suggest that in the field of Neurology, English-written research is less collaborative than Spanish-written research as far as authorship is concerned. It could also be that on some occasions Spanish sub-authors were given the status of co-authors although their contribution to the reported research was not really meaningful. As Gómez et al. (2006) so rightly put forth, in the Spanish-speaking academic community there is so much pressure to publish that scientists need to figure as co-authors in the greatest possible number of scientific papers. By contrast, the higher presence of sub-authors and unnamed individuals (who usually appear in the ACK spaces) in the English sample runs parallel with the higher number of ACKs and their length already commented upon in sub-section 4.1 and table 1 . These results would then underscore the fact that the authors of the RPs published in BMC Neurology have many more debts to recognize and are more willing, or feel more obliged to do so, than the authors of the RPs published in Revista Española de Neurología.

\subsection{Types of collaboration}

Table 4 illustrates the different types of collaboration, which are based on all the countries indicated in all the address fields in the whole sample.

- Local collaboration, also called "intramural" collaboration (Glänzel/Schubert 2004: 258), i.e. collaboration among scientists working within one department, research group or institute in the same town.

- National collaboration (researchers affiliated in different towns in the same country).

- Local + national collaboration, which usually apply to authors belonging to the same research group who work in different towns throughout the country.

- International collaboration, or "multi-national" collaboration (Glänzel/Schubert 2004: 260), which refers to scientists affiliated in different countries. 
- Local collaboration + international collaboration.

- National collaboration + international collaboration.

- Local collaboration + national collaboration + international collaboration.

Tab. 4: Types of collaboration in English and Spanish RPs

\begin{tabular}{|l|c|c|}
\hline Collaboration type & No. RPs (English) & No. RPs (Spanish) \\
\hline no collaboration & 1 (Israel) & 1 (Spain) \\
\hline local & 44 & 71 \\
\hline national & 10 & 8 \\
\hline local + national & 18 & 14 \\
\hline international & 3 & 1 \\
\hline local + international & 12 & 0 \\
\hline national + international & 3 & 1 \\
\hline local + national + international & 9 & 100 \\
\hline Total & 100 & 4 \\
\hline
\end{tabular}

\section{English sample}

- Local collaboration: the USA (6 RPs); Norway and Taiwan (4 RPs each country); Germany and Japan (3 RPs each country); Canada, Pakistan, Spain, Sweden and the UK (2 RPs each country); Australia, Austria, China, Egypt, Greece, Iran, Kuwait, Lithuania, Portugal, Singapore, Slovenia, South Korea, Thailand and The Netherlands (1 RP each country)

- National collaboration: Germany, Japan, Spain, The Netherlands, the UK (1 RP each country); USA (5 RPs)

- Local + national collaboration: Spain and the USA (4 RPs each country); Germany (3 RPs); China, France, Italy, South Korea, Sweden, The Netherlands and the UK (1 RP each country)

- International collaboration: Germany and Switzerland; India and the UK; Austria, Germany and the USA (1 RP each block)

- Local + international collaboration: Belgium and Germany (2 RPs); Canada and Germany; Austria and Egypt; Pakistan and the UK; Sweden and the USA; Switzerland and The Netherlands; Australia, Belgium and Germany; Germany, Greece and Italy; Australia, Hong Kong and the UK; Finland, Greece and the USA; Australia, Italy, Sweden and the USA (1 RP each block)

- National + international collaboration: Canada, the UK and the USA; Italy and the USA; Switzerland and the USA (1 RP each block)

- Local + regional + international collaboration: Germany and Switzerland; Belgium and the USA; Estonia and Finland; Italy and the UK; Switzerland and The Netherlands; Sri Lanka and the USA; Sweden and the USA; France and Switzerland; France, Germany, the UK and the USA (1 RP each block)

\section{Spanish sample}

- Local collaboration: Argentina and México (3 RPs each country); Brazil, Colombia, Uruguay and Venezuela (2 RPs each country); Chile (4 RPs); Costa Rica, Honduras and Hungary (1 RP each country); Cuba (8 RPs); Spain (42 RPs) 
- National collaboration: Brazil (1 RP); Spain (7 RPs)

- Local + national collaboration: Spain (14 RPs)

- International collaboration: Chile and Italy; Colombia and Spain; Canada, Peru and the USA; Spain and the USA (1 RP each block)

- Local + international collaboration: Spain and Uruguay (1 RP)

- $\quad$ Local + national + international collaboration: Colombia and USA (1 RP)

Except one RP from block A (2001) in each language with only one author, the remaining RPs were all written in collaboration. In the English sample, the number of authors per RP runs from two authors to 25 authors, whereas in the Spanish set it also runs from two authors to 24 authors. It is worth pointing out that the 25 authors of the English-written RP are Spanish scientists who work in different public institutions throughout Spain, as in other five articles that also have a Spanish authorship. To the extent that the two journals analysed in this study are highly representative of the field of Neurology, it can be said that neurologists practically never work in isolation and that co-authorship predominates in the referred medical sub-field - $99 \%$ of all RPs published between 2001 and 2012 were co-authored.

The English set includes authors from 33 countries, whereas in the Spanish set only 16 countries are involved. In the English corpus, 27 countries do not have English as their official language (Austria, Belgium, China, Egypt, Estonia, Finland, France, Germany, Greece, India, Iran, Italy, Japan, Kuwait, Lithuania, Norway, Pakistan, Portugal, Slovenia, Spain, Sri Lanka, South Korea, Sweden, Switzerland, Taiwan, Thailand, The Netherlands). In the Spanish context, there is one RP written by authors affiliated in Hungarian institutions and one of them has Spanish surnames, like the authors who signed the RPs mentioning Anglo-American, Brazilian, Canadian and Italian institutions. It could thus be inferred that it is about Spanish-language scientists who are doing research in Brazil, Canada, Italy and the USA. Conversely, the English sample does not include any RP signed by authors from the Latin-American continent. The fact that the English set includes so few papers written by Spanish-speaking authors could be understood, at least in the RPs analysed in this study, as a reluctance from these authors to publish in an Anglo-American journal of Neurology, perhaps because they think that they do not have a good mastery of English, which could have an influence on the acceptance rate for publication in the present English-research world. Somewhat surprising is the fact that only two RPs show the collaboration between Spain and Latin-American countries (Colombia and Uruguay) in spite of sharing a common language as a consequence of ancient colonial ties.

Other questions related to the different types of collaboration should also be mentioned. If the frequency of RPs that reflect 'national' and 'international' collaboration is more or less the same in both samples, on the contrary, the incidence of 'local', 'local + international' and 'local + national + international' collaboration is very different from one corpus to the other. In the Spanish set there is no 'national + international' collaboration, which appears in three English-written RPs, and only in six Spanish-written RPs is 'international' collaboration represented compared to 27 English-written RPs. The larger network of international co-publications in English could be with no doubt attributed to the internationalization reached by this language, and thus its wider audience/readership. Moreover, in both corpora and mainly in the Spanish sample, 'local' collaboration clearly predominates above the remaining variants. These results are in agreement with Sugimoto's and Cronin's (2012) statement that geographical proximity plays an important role for working teams. Finally, it could be stated that the country most involved in the seven types of collaborative research published in BMC Neurol- 
ogy is the USA (26 RPs), followed by Germany (15 RPs) and UK (10 RPs). It is not surprising that the USA figure on the top of the scale as BMC Neurology is an Anglo-American journal, but what is somewhat surprising is that Germany, which does not have English as its official language, precedes the UK. This would perhaps reflect that the German scientific collaborative networks and webs of cognitive ties are more firmly established than the British ones.

\subsection{Comparative diachronic analysis}

Although this study did not include any diachronic analysis within its main objectives, I thought it could be useful to dedicate a brief section to this issue by examining the different periods established in order to verify what has happened to the number of RPs with ACKs, ACK length and the number of authors. If we have a look at table 5, which focuses on the English sample, we can appreciate a slow but steady increase in the number of RPs with ACKs and of ACK words from block A to block E.

Tab. 5: Evolution of the frequency of RPs with ACKs, of the ACK length and of the word average per ACK and period in the English sample

\begin{tabular}{|l|c|c|c|}
\hline English & No. RPs with ACKs & ACK length & Word average/ACK \\
\hline A (2001) & 14 & 482 & 34.43 \\
\hline B (2004) & 16 & 566 & 35.38 \\
\hline C (2007) & 18 & 895 & 49.72 \\
\hline D (2010) & 20 & 1116 & 55.80 \\
\hline E (2012) & 20 & 1312 & 65.80 \\
\hline Total & 88 & 4371 & 49.67 \\
\hline
\end{tabular}

Table 6 deals with the same analysis as table 5 but centred on the Spanish sample. As in the English set, the highest score of RPs with ACKs and of words making up the ACKs appears in block E although not in the same proportion as the data relating to the English corpus.

Tab. 6: Evolution of the frequency of RPs with ACKs, of the ACK length and of the word average per ACK and period in the Spanish sample

\begin{tabular}{|l|c|c|c|}
\hline Spanish & No. RPs with ACKs & Total words/ACKs & Word average/ACK \\
\hline A (2001) & 4 & 96 & 24.00 \\
\hline B (2004) & 6 & 192 & 32.00 \\
\hline C (2007) & 9 & 309 & 34.33 \\
\hline D (2010) & 10 & 353 & 35.30 \\
\hline E (2012) & 12 & 451 & 37.58 \\
\hline Total & 41 & 1402 & 34.19 \\
\hline
\end{tabular}


Table 7 displays the figures related to authorship, and in both samples an increase can also be appreciated from block A to block E.

Tab. 7: Total and authorship average per period in English and Spanish RPS

\begin{tabular}{|l|c|c|c|c|}
\hline No. authors & English & Author average & Spanish & Author average \\
\hline A (2001) & 96 & 4.8 & 89 & 4.45 \\
\hline B (2004) & 106 & 5.3 & 96 & 4.8 \\
\hline C (2007) & 136 & 6.8 & 175 & 8.75 \\
\hline D (2010) & 141 & 7.05 & 248 & 12.4 \\
\hline E (2012) & 193 & 9.65 & 275 & 13.75 \\
\hline Total & 672 & 6.72 & 883 & 8.83 \\
\hline
\end{tabular}

The increase in the number of RPs with ACKs can be accounted for by a stricter authors' compliance with the journal guidelines, whereas the increase in the ACK length is likely due to the more diverse ACK categories and to the growing number of people to acknowledge. As for the growth in scientific collaboration, which was already mentioned in section 4.4 (Types of collaboration), it is related to the fact that scientific collaboration networks have become more and more complex over time because of the growing complexity of scientific research.

\section{Conclusions}

This paper has examined the frequency, length and content of acknowledgments, as well as the collaboration practices in English- and Spanish-written research papers published in the field of Neurology with the aim of discovering the differences and similarities between them. The results of this study have shown that the ACKs included in the English corpus are more frequent, longer and varied than those contained in the Spanish sample. In both corpora, financial funding is more frequently acknowledged than the other types of ACK categories, although to a greater extent in the English set than in the Spanish set, where on many occasions authors do not count on any kind of support, mainly economical, probably because of less funds devoted to research, development and innovation, by national and local institutions. Our findings have also disclosed that the total number of authors recorded is higher in Spanish than in English. Conversely, English sub-authors and unnamed individuals outnumber their Spanish counterparts. Some of the differences observed could probably be attributed to the definitions given in this paper to the categories "authorship" and "sub-authorship" and to the different contexts in which English- and Spanish-speaking scientists work and perform their research.

Nevertheless, it should be stated that the results of this study may not be representative of all medical ACKs in the field of English- and Spanish-published Neurology since a limited and randomly selected sample of texts was examined. It would perhaps be advisable to corroborate them with a larger sample from the same field and also to contrast them with ACKs in other medical sub-fields, in other kinds of articles and in other languages. Such research would surely provide more interesting data on the field explored here. Altogether, and as ACKs "constitute a potentially rich source of insight in the rules of engagement which define the bases of collaboration, social exchange and interdependence within academia" (Cronin 1995: 108), the features found would probably enlarge the insight into ACK practices and contribute to enrich previous research on this issue. 


\section{References}

Atkinson, Dwight (1999): Scientific Discourse in Sociohistorical Context: The Philosophical Transactions of the Royal Society of London. 1675-1975. Mahwah (NJ): Erlbaum.

Beckelman, Justin E./Li, Yan/Gross, Cary P. (2003): “Scope and impact of financial conflicts of interest in biomedical research: A systematic review." JAMA 289: 454-465.

Ben-Ari, Eyal (1987): "On acknowledgments in ethnographies." Journal of Anthropological Research 43.1: 63-84.

Connor, Ulla/Moreno, Ana I. (2005): "Tertium comparationis: A vital component in contrastive rhetoric research." Directions in Applied Linguistics: Essays in Honor of Robert B. Kaplan. Eds. Paul Bruthiaux/Dwight Atkinson/William G. Eggington/William Grabe/Vaidehi Ramanathan. Clevedon: Multilingual Matters. 153-164.

Cronin, Blaise (1995): The Scholar's Courtesy. The Role of Acknowledgments in the Primary Communication Process. Cambridge/Los Angeles: Taylor Graham.

Cronin, Blaise (2005): The Hand of Science: Academic Writing and its Rewards. Lanham (MD): Scarecrow Press.

Cronin, Blaise/McKenzie, Gail/Stiffler, Michael (1992): "Patterns of acknowledgments." Journal of Documentation 48.2: 107-122.

Cronin, Blaise/Shaw, Debora/La Barre, Kathryn (2004): “Visible, less visible and invisible: Patterns of collaboration in $20^{\text {th }}$ century chemistry." Journal of the American Society for Information Science and Technology 55.2: $160-168$.

Cronin, Blaise/Franks, Sara (2006): "Trading culture: Resource mobilization and service rendering the life sciences as revealed in the journal article's paratext." Journal of the American Society for Information Science and Technology 57.14: 1909-1918.

Davis, Charles/Cronin, Blaise (1993):"Acknowledgments and intellectual indebtedness: A bibliometric conjecture." Journal of the American Society for Information Science and Technology 44.10: 590-592.

Genette, Gerard (1997): Palimpsests: Literature in the Second Degree. Lincoln: University of Nebraska Press.

Gesuato, Sara (2004): "Acknowledgments in PhD dissertation: The complexity of thanking." Lingua inglese e mediazione linguistica. Ricerca e didattica con supporto telematico. Eds. Carol Taylor Torsello/Maria Gracia Busà/Sara Gesuato. Padova: Unipress. 273-318.

Giannoni, Davide S. (1998): "The genre of journal acknowledgments: Findings of a cross-disciplinary investigation." Linguistica e Filologia 6: 61-84.

Giannoni, Davide S. (2002): “Worlds of gratitude: A contrastive study of acknowledgment texts in English and Italian research articles." Applied Linguistics 23.1: 1-31.

Giannoni, Davide S. (2006): "Book acknowledgments across disciplines and texts." Academic Discourse across Disciplines. Eds. Ken Hyland/Marina Bondi. Bern: Lang. 151-175.

Giles, Lee/Councill, Isaac G. (2004): “Who gets acknowledged? Measuring scientific contributions through automatic acknowledgement indexing." National Academy of Sciences 101.5: 17599-17604.

Glänzel, Wolfgang/Schubert, András (2004): "Analyzing scientific networks through co-authorship." Handbook of Quantitative Science and Technology Research. Eds. Henk F. Moed/Wolfgang Glänzel/Ulrich Smoch. Dordrecht: Kluwer Academic Publishers. 257-276.

Gómez, Isabel/Sancho, Rosa/Bordons, María/Fernández, María Teresa (2006): “La I+D en España a través de sus publicaciones y patentes." Radiografía de la investigación pública española. Eds. Jesús Sebastián/Emilio Muñoz. Madrid: Biblioteca Nueva. 275-302.

Heffner, Alan G. (1981): "Funded research, multiple authorship and sub-authorship collaboration in four disciplines." Scientometrics 3.1:5-12. 
Hyland, Ken (2003): “Dissertation acknowledgments: The anatomy of a Cinderella genre." Written Communication 20.3: 242-268.

Hyland, Ken (2004): "Graduates' gratitude: The generic structure of dissertation acknowledgments." English for Specific Purposes 23.3: 303-324.

Hyland, Ken/Tse, Polly (2004): "II would like to thank my supervisors': Acknowledgments in graduate dissertations." International Journal of Applied Linguistics 14.2: 259-275.

Laband, David N./Tollison, Robert D./Karahan, Gokhan R. (2002): "Quality control in economics." Kyklos 55.3: 315-334.

McCain, Katherine W. (1991): “Communication, competition and secrecy: The production and dissemination of research-related information in genetics." Science, Technologies and Human Values 16.4: 491-516.

Moreno, Ana I. (2008): "The importance of comparable corpora in cross-cultural studies." Contrastive rhetoric: Reaching to Intercultural Rhetoric. Eds. Ulla Connor/Ed Nagelhout/William Rozycki. Amsterdam: Benjamins. 25-41.

Nour, Samia S. (2005): "Science and technology development indicators in the Arab region: A comparative study of Arab Gulf and Mediterranean countries." Science, Technology and Society 10.2: 249-274.

Patel, Narsi (1973): "Collaboration in the professional growth of American sociology." Social Science Information 12.6: 77-92.

de Pedro-Cuesta, Jesús/Virués-Ortega, Javier/Saturio Vega, Manuel/Seijo-Martínez, Manuel/Saz, Pedro/Rodríguez, Fernanda/Rodríguez-Laso, Ángel/Reñé, Ramón/de las Heras, Susana P./Mateos, Raimundo/ Martínez-Martín, Pablo/Manubens, José M./Mahillo-Fernández, Ignacio/López-Pousa, Secundino/Lobo, Antonio/Reglà, Jordi L./Gascón, Jordi/García, Francisco José/Fernández-Martínez, Manuel/Boix, Raquel/ Bermejo-Pareja, Félix/Bergareche, Alberto/Benito-León, Julián/de Arce, Ana/del Barrio, José L. (2009): "Prevalence of dementia and major dementia subtypes in Spanish populations: A reanalysis of dementia prevalence surveys, 1990-2008." BMC Neurology. Retrieved from http//www.biomedcentral.com/14712377/9/55.

Salager-Meyer, Françoise/Alcaraz Ariza, María Á./Pabón Berbesí, Maryelis (2009): “Backstage solidarity in Spanish- and English-written medical research papers: Publication context and the acknowledgment paratext." Journal of the American Association of Information Science and Technology 60.2: 307-317.

Salager-Meyer, Françoise/Alcaraz Ariza, María Á./Pabón Berbesí, Maryelis (2010): “Hidden influencers and the scholarly enterprise: A cross cultural/linguistic study of acknowledgments in medical research articles." English for Profession and Academic Purposes. Eds. Miguel F. Ruiz-Garrido/Juan C. Palmer-Silveira/Inmaculada Fortanet-Gómez. Amsterdam: Rodopi. 43-56.

Salager-Meyer, Françoise/Alcaraz Ariza, María Á./Luzardo Briceño, Marianela/George Jabbour (2011): “Scholarly gratitude in five geographical contexts: A diachronic and cross-generic approach of the acknowledgment paratext in medical discourse (1950-2010)." Scientometrics 86.3: 763-784.

Sugimoto, Cassidy R./Cronin, Blaise (2012): "Bio-bibliometric profiling: An examination of multifaceted approaches to scholarship." Journal of the American Society for Information Science and Technology 63.3: 450-468.

María Ángeles Alcaraz

Dept. of English Studies

University of Alicante, Spain

Carretera de San Vicente del Raspeig $s / n$

03690 Alicante

ariza@ua.es 